\title{
The pathogenesis and treatment of polycystic ovary syndrome: What's new?
}

\author{
Sylwia Bednarska ${ }^{A-D}$, Agnieszka Siejka ${ }^{B-F}$ \\ Department of Clinical Endocrinology, Medical University of Lodz, Łódź, Poland \\ A - research concept and design; $\mathrm{B}$ - collection and/or assembly of data; $\mathrm{C}$ - data analysis and interpretation; \\ $D$ - writing the article; $E$ - critical revision of the article; $F$ - final approval of article
}

\section{Address for correspondence \\ Sylwia Bednarska}

E-mail: friosylvie@op.pl

\section{Funding sources}

none declared

Conflict of interest

none declared

Received on June 11, 2015

Revised on August 09, 2015

Accepted on September 10, 2015

\begin{abstract}
Polycystic ovary syndrome (PCOS) is currently the leading cause of menstrual complications in women. It is characterized by clinical and/or biochemical hyperandrogenism, ovulation abnormalities and the presence of enlarged and/or polycystic ovaries in ultrasound images (12 or more small bubbles located circumferentially and/or ovarian volume $>10 \mathrm{~mL}$ ). It is often comorbid with hyperinsulinemia, dyslipidemia, overweight or obesity, and is a risk factor for the development of diabetes and cardiovascular diseases (CVDS). The treatment of patients with PCOS depends on the prevailing symptoms. The aim of this paper is to present the etiopathogenesis, clinical and biochemical implications, and non-pharmacological and pharmacological treatment options - those approved by worldwide scientific organizations as well as new therapies whose initial results are encouraging enough to prompt researchers to explore them further.
\end{abstract}

Key words: treatment, statins, metformin, PCOS

DOI

10.17219/acem/59380

\section{Copyright}

Copyright by Author(s)

This is an article distributed under the terms of the

Creative Commons Attribution Non-Commercial License

(http://creativecommons.org/licenses/by-nc-nd/4.0/) 
Polycystic ovary syndrome (PCOS), also known as the Stein-Leventhal syndrome, is one of the most common endocrinopathies among women of reproductive age. It is estimated that it affects $3-15 \%$ of all women. An abnormality in the ovaries is the primary cause of the disorder, but additional agents, such as obesity and environmental factors, affect the development of individual symptoms. ${ }^{1}$ The Rotterdam criteria (2003) are the most widely used and relevant criteria for the diagnosis of PCOS. The disorder is diagnosed if 2 of the 3 specified conditions are met: (1) hyperandrogenism (detected by clinical and/or biochemical testing) (2) ovulation abnormalities, and/or (3) 12 or more cysts on one ovary and/or ovarian volume $>10 \mathrm{~mL}$. There are also 2 other definitions of the syndrome in addition to the Rotterdam criteria. According to the criteria proposed by the National Institutes of Health (NIH, 2009), a diagnosis of PCOS involves detection of clinical or biochemical hyperandrogenism and chronic ovulation disorders. The Androgen Excess Society (2006), on the other hand, treats hyperandrogenism as the basic PCOS disorder and the prerequisite for a diagnosis, in combination with one of the 2 remaining Rotterdam criteria. ${ }^{2}$ In all these cases, PCOS can be diagnosed after Cushing's syndrome, congenital adrenal hyperplasia and/or androgen-secreting tumors have been ruled out.

Based on the Rotterdam criteria, 4 phenotypes of PCOS can be distinguished: (1) classic: hyperandrogenism $(\mathrm{H})$, ovulation disorders $(\mathrm{O})$ and a polycystic ovary $(\mathrm{P})$ detected by USG (HOP); (2) with hyperandrogenism and ovulation disorders, but with a normal ovarian USG image (HO); (3) with hyperandrogenism and a polycystic ovary USG image, but without ovulation disorders (HP); (4) with ovulation disorders and a polycystic ovary USG image, but without evidence of hyperandrogenism $(\mathrm{OP}){ }^{1-3}$

Despite these seemingly clear criteria, the etiology of PCOS remains unknown, and precise treatment procedures have not been established. PCOS therefore continues to be the object of research and scientific inquiry. In this paper, the postulated causes and possible effects of the clinical and biochemical syndrome are discussed, along with currently accepted and novel therapeutic methods.

\section{Etiopathogenesis}

A defect of the ovarian cells (most likely theca cells) is the underlying cause of PCOS, resulting in excessive androgen synthesis and the clinical and biochemical symptoms of the disease. ${ }^{1,2}$ In the literature, reference is made to the participation of genetic factors, including ethnicity; there is a higher frequency of PCOS in Spanish, native American and Mexican women. ${ }^{41}$ In their original description of the syndrome, Stein and Leventhal emphasized that a high ratio of luteinizing hormone (LH) to follicle-stimulating hormone (FSH) is one of the basic disorders. It has also been suggested that the underlying causes of PCOS include increased frequency of gonadotropin-releasing hormone $(\mathrm{GnRH})$ pulses that stimulate the theca cells to produce androgen; decreased levels of FSH (and thus a defect in the late luteal and early follicular phases); insulin resistance via a post-receptor defect in the fat tissue and skeletal muscles (abnormal phosphorylation of tyrosine kinase); pancreatic beta-cell dysfunction; and obesity. ${ }^{1,3}$ It is often impossible to determine definitively what is a cause and what is an effect in the development of PCOS. In addition, it is generally recognized that obesity increases menstrual disorders and hyperandrogenism, while weight reduction reduces the clinical signs. Reduced insulin sensitivity is an important issue in both obese and underweight women with PCOS; it is estimated that $50-70 \%$ of women with the condition show insulin resistance of varying intensities. ${ }^{3}$

\section{Genetic factors}

The influence of genetic factors was highlighted by Davies et al., who proved that mothers of women with PCOS are more likely to have a cardiovascular disease and that their risk of hypertension is twice as high as mothers of women without PCOS, while fathers of women with PCOS are twice as likely to have heart disease and 4 times more likely to have experienced cerebral stroke. ${ }^{5}$ Tan et al. emphasized the increased likelihood of insulin resistance (IR) associated with certain genes (such as INSIG2 and MC4R) and the particular impact of TCF7L2 SNP on the development of diabetes mellitus type 2 (DM2) and body weight gain in patients with PCOS (a per-allele weight gain of $\left.1.56 \mathrm{~kg} / \mathrm{m}^{2}\right){ }^{6}$ The etiology of IR was also discussed by Fica et al., who, while highlighting the complex mechanisms of PCOS, identified insulin receptor autophosphorylation, reduced levels of phosphatidylinositol-3-kinase in muscle tissue and visceral adiposity as probable mechanisms. $^{7}$

\section{Hyperinsulinemia/insulin resistance}

Hyperinsulinemia in combination with pancreatic beta cell dysfunction results in an increased risk of many diseases, including type 2 diabetes, hypertension, dyslipidemia, endothelial dysfunction, atherosclerosis and cardiovascular diseases. Insulin also stimulates the theca cells of the ovary to produce excessive testosterone, which is responsible for the clinical symptoms of hyperandrogenism (acne, hirsutism, alopecia). ${ }^{8}$ Cardiovascular risk is also elevated in women who are chronic smokers, as demonstrated in a recent work by Marotti et al. ${ }^{4}$ 


\section{Inflammation}

The role of inflammation in PCOS has been the subject of a number of studies, and direct correlations have been found between increased levels of inflammation markers (CRP, ferritin, leukocyte TNF- $\alpha$, IL-6, IL-18) and the development of PCOS. Other contributors include elevated levels of PAI1 and free fatty acids, influencing excessive phosphorylation of serine residues, leading to a rise in insulin resistance. ${ }^{9}$ Newly emerging issues include a pathogenic correlation of the markers of iron overload with PCOS. Increased levels of ferritin and transferrin and a higher frequency of the HP2/HP2 genotype of the haptoglobin $\alpha$ chain have been observed, causing a reduction of anti-inflammatory cytokines and antioxidant molecules, leading to a state of chronic inflammatory response. ${ }^{10,11}$

\section{Clinical implications}

In addition to hyperandrogenism and its related complications, the most common abnormalities associated with PCOS include menstrual disorders (amenorrhea or oligomenorrhea), often leading to infertility (in $73-74 \%$ of the cases), abdominal obesity (30-70\%) and type 2 diabetes (approximately 10\%).1,7 The prevalence of metabolic disorders in women with PCOS is higher than in the healthy population, with type 2 diabetes occurring at the highest frequency (3-7 times), especially in Indians. ${ }^{2,44}$ Other frequent disorders include hirsutism (85-90\%) symptoms of metabolic syndrome (MS, approximately 40\%), obesity/ overweight (40-60\%), lipid disorders, arterial hypertension (approximately 20\%) (Table 1). It is worth noting that any excessive weight in these patients impairs the regularity of menstrual bleeding and responses to metformin and insulin treatment, exacerbates the symptoms of hyperandrogenism and also increases cardiovascular risk (Fig. 1). 3,11,15

Recent reports have revealed a close correlation between mental disorders and clinical PCOS symptoms such as acne, hirsutism, infertility, obesity and a poorer quality of life. A higher frequency of depression, drug-related and bipolar disorders, bulimia, anorexia or non-spe-

Table 1. Frequency of typical disorders in PCOS

\begin{tabular}{|lc|}
\hline Abnormality & Frequency \\
\hline Infertility & $73-75 \%$ \\
Hirsutism & $85-90 \%$ \\
Metabolic syndrome: & $40 \%$ \\
abdominal obesity & $30-70 \%$ \\
diabetes type 2 & $10 \%$ \\
arterial hypertension & $20 \%$ \\
disturbed lipid metabolism & unavailable \\
\hline
\end{tabular}

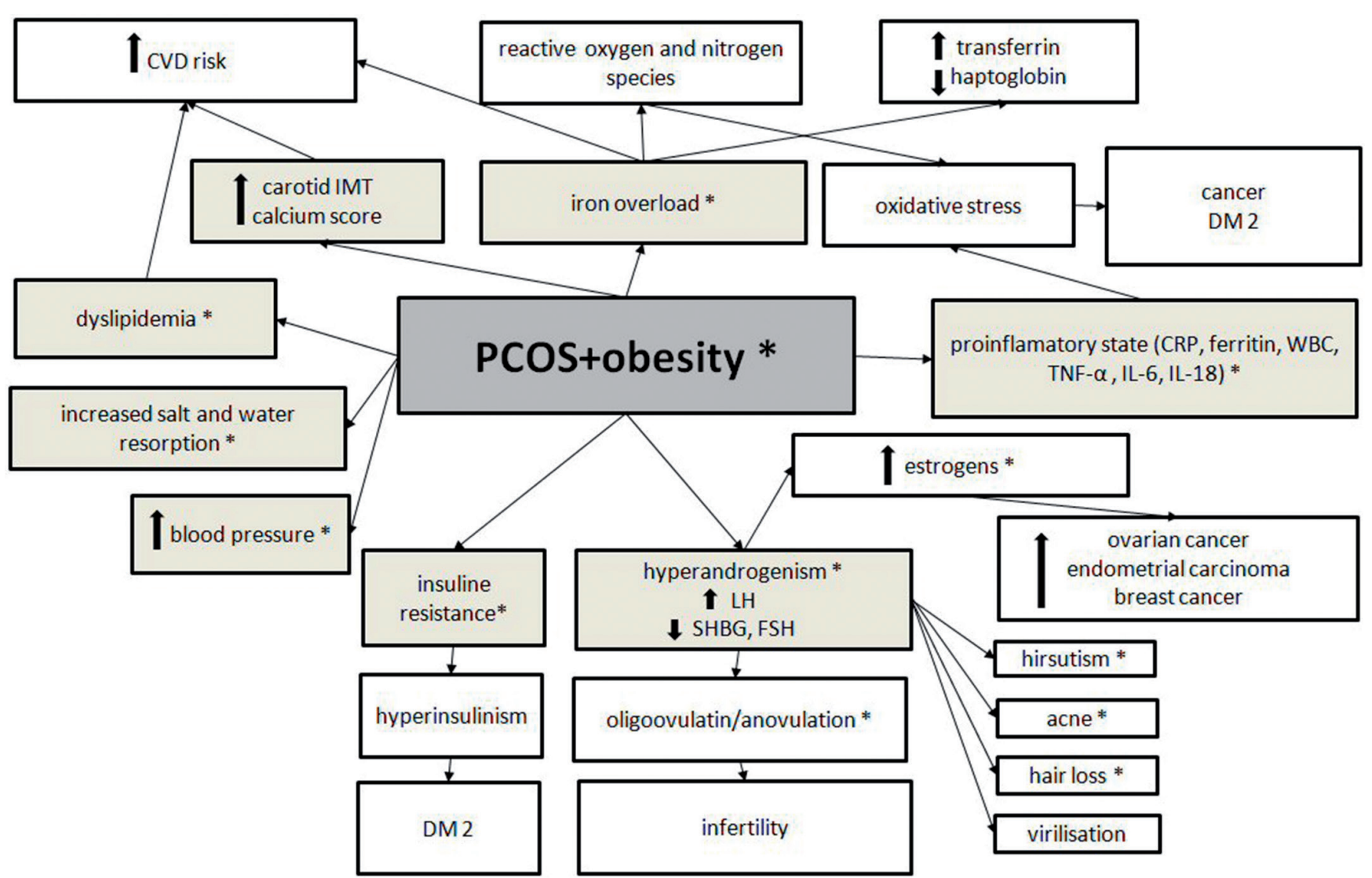

Fig. 1. A chart of correlated symptoms in obese PCOS patients and possible targets for treatment $\left(^{*}\right)$ 
cific dietary disorders was noted among PCOS patients. ${ }^{12}$ Chronic hyperandrogenemia, which leads to increased aromatization of androgens to estrogens in adipose tissue, may contribute further to the development of hormone-dependent tumors, such as endometrial, mammary or ovary neoplasms. ${ }^{13}$

Taking into account the considerations presented above, it is advisable for routine oral glucose tolerance testing (OGTT) to be performed in obese women with PCOS (but routine OGTT is not necessary for women with normal body weight). Patients diagnosed with PCOS are included in the groups at risk of developing diabetes, in accordance with the standards of the Polish Diabetes Association. ${ }^{14}$

\section{Biochemical disorders}

In polycystic ovaries, abnormal steroidogenesis is manifested primarily by increased production of androgens and estradiol, and the malfunctioning hypothalamic-pituitary-ovarian axis is manifested by increased secretion of $\mathrm{LH}$, anti-mullerian hormone (AMH), a higher frequency of GnRH pulses and a reduction in FSH concentration. ${ }^{1,2}$ These correlations (most importantly the participation of androgens) are associated with a disturbed lipid profile: an increase in very-low-density lipoprotein (VLDL), low-density lipoprotein (LDL) and triglycerides (TG), and a decrease in HDL- and LDL-cholesterol, regardless of body weight. Dyslipidemia, coagulation disorders, increased plasminogen activator inhibitor 1 (PAI1) and other metabolic consequences, increases in the coronary artery calcium score and resultant increases in carotid intima-media thickness (CIMT) lead to an increase in the risk of cardiovascular disorders. ${ }^{15}$ Obesity/ overweight coexisting with PCOS can lead to iron deficiency (through increased production of proinflammatory cytokines, oxidative stress and a resultant increase in the levels of hepcidin, inhibiting the absorption of iron from enterocytes), and thus the signs of anemia in those women. There are many reports on the role of iron deficiency in the development of diabetes and its complications. The opposite situation also occurs, and iron overload in obese women with PCOS as measured by levels of ferritin, soluble transferrin receptor (sTfR), hepcidin and heme iron, is also a risk factor for insulin resistance, type 2 diabetes and cardiac disease. Reducing the consumption of red meat and the use of iron-zinc chelators may be beneficial. ${ }^{10} \mathrm{Bu}$ et al. have shown a relationship between elevated serum levels of preptin (34-amino acid protein secreted from the beta cells of the pancreas along with insulin) with impaired glucose tolerance (IGT) in both PCOS patients and healthy controls, but found no correlation with PCOS status. ${ }^{16}$

The results of the available studies suggest that PCOS entails subclinical damage at the cellular level at an early stage of the disease, with the possibility of many adverse long-term sequelae. This indicates that it is necessary to implement prevention strategies and interventions that must sometimes be started at an early stage in the development of the symptoms.

\section{Currently applied treatment}

The procedures used in PCOS treatment depend primarily on the desired clinical effect: infertility treatment, regulation of menstrual disturbances, alleviation of the symptoms of hyperandrogenism or obesity treatment.

For women wishing to conceive, clomifene still remains first-line therapy. It is an estrogen receptor modulator that directly affects the hypothalamic-pituitary axis, acting rapidly and effectively; $75 \%$ of the pregnancies in patients using clomifene are conceived in the first 3 months of treatment. ${ }^{1}$

Another drug used with PCOS patients wishing to restore fertility is metformin; its effectiveness can be observed after 6 months of treatment. ${ }^{1,2}$ The role of metformin in inducing ovulation is still controversial. It is known for certain that metformin contributes to reducing insulin levels and androgens, thus restoring the regularity of the ovulatory cycle and periods. Metformin is a biguanide derivative, well-known for many years; it not only reduces insulin resistance and blood pressure, improves the lipid profile and antioxidant characteristics and increases the levels of sex hormone binding globulin (SHBG), but also (through its pleiotropic effect on the vascular endothelium) acts to protect the cardiovascular system. ${ }^{21,22}$ In addition, its dose-dependent protective effect against the risk of developing endometrial, mammary, intestinal and hepatic cancer has been reported by several authors. ${ }^{19,20}$ Although many researchers claim that metformin plays a role in reducing body weight, a recent study has contradicted that view, pointing to the absence of any such correlation; the only possible relationship involves redistribution of active visceral fat to inactive subcutaneous fat. ${ }^{21}$ The starting dose of $500 \mathrm{mg}$ once a day at lunch time, increased to 3 tablets $/ 24 \mathrm{~h}$ when tolerance is good, does not influence insulin resistance if it is not applied too long. ${ }^{1}$ Tang et al. have shown a negative correlation in the reduction of insulin resistance after 6 months of therapy, as opposed to a study by Oppelt et al. that found increased insulin resistance after a 2-year period of intervention. . $2,23^{2}$ Although older reports did not confirm the effect of metformin on clinical symptoms related to hyperandrogenism, recent data indicate effects of that kind, especially in reducing skin problems (hirsutism, acne, acanthosis nigricans). ${ }^{1,12}$

Other therapeutic options for women with the problem of infertility in PCOS are gonadotropins, used to induce ovulation, or laparoscopic surgery for patients resistant to pharmacological therapies. Laparoscopic techniques that 
can successfully trigger ovulation include ovarian biopsy and electrocautery, laparoscopic ovarian drilling, transvaginal hydrolaparoscopy, ultrasound guided transvaginal ovarian needle drilling or laparoscopic ovarian multi-needle intervention. ${ }^{1,43}$

PCOS patients whose goal is not pregnancy are usually advised to use oral contraceptives (OCP), which effectively restore the rhythm of bleeding, reduce hyperandrogenism and also contribute to reducing the risk of endometrial hyperplasia. ${ }^{1}$ The effects of excessive androgen synthesis on a patient's appearance - hirsutism, acne, alopecia, acanthosis nigricans - are among the most frequent problems causing patients with PCOS to seek medical care. They are also among the main causes of deterioration in their quality of life, chronic stress and mental disorders, including depression. ${ }^{12}$ The pharmacological therapies for these problems primarily make use of antiandrogen drugs, such as cyproterone acetate in combination with ethinyl estradiol (OCP), spironolactone or metformin.

Drugs that are not normally used in the treatment of hyperandrogenism, but which can be taken into consideration, include long-acting GnRH analogs, ketoconazole, glucocorticoids, flutamide and finasteride.

Local procedures intended to reduce excessive hair growth include beauty treatments, such as hair removal, electrolysis, laser destruction of the follicles and/or application of a cream containing $13.9 \%$ ornithine decarboxylase inhibitor and $13.9 \%$ eflornithine. Studies have shown that the substances contained in the cream, applied twice a day for 6 months reduce hair growth. The cream is well tolerated and, in combination with laser epilation, is more effective than hair removal methods used alone. ${ }^{25}$

Another goal of therapy in PCOS is to reduce obesity, where in addition to lifestyle modification, diet and pharmacological therapy with metformin, surgical methods have been applied. It has been demonstrated that bariatric procedures for the treatment of obesity greatly improve the profile of patients with PCOS by preventing metabolic syndrome; reducing body weight, blood pressure and the risk of cardiovascular diseases; restoring normal function of the hypothalamic-pituitary axis; improving reproductive function; and also, as demonstrated by Eid et al., normalizing blood pressure in approximately $78 \%$ of treated patients with previous hypertension. ${ }^{24}$

\section{New therapeutic options}

Among the new therapeutic options for PCOS patients, isotretinoin - a popular drug used to treat acne - deserves to be mentioned. In a study by Cakir et al., women with acne (46 without PCOS and 50 with PCOS) received intramuscular injections of $0.5-1 \mathrm{mg} / \mathrm{kg} / \mathrm{dL}$ isotretinoin, and the effects of the treatment were observed after one and 2 years. In both groups, the therapy was highly effective (91.6\% achieved complete remission of their acne), which may lead to the use of isotretinoin as a first line treatment for PCOS patients with acne, second only to oral contraceptive therapy. Isotretinoin may improve the patients' reduced AMH levels, which correlate with elevated androgen levels. ${ }^{26}$ However, the results of a recently published study by Cetinözman et al. indicate that severe acne does not correlate with the level of androgens or sensitivity to insulin. Isotretinoin therapy not only fails to produce the desired clinical effect but contributes to an increase in body weight and triglyceride levels in the patients. ${ }^{27}$ Due to the high costs, the multitude of potential adverse effects and its problematic effectiveness, isotretinoin treatment is not yet widely recommended in PCOS, although the prospects are promising.

Androgenetic alopecia (AGA) is another problem associated with PCOS. Antiandrogenic drugs (cyproterone acetate) and inhibitors of 5-alpha reductase (finasteride) are particularly effective in hyperandrogenism accompanied by increased body mass, but a good response has also been observed with a $2 \%$ solution of a drug called minoxidil used twice a day for at least 6 months. This chemical, after it is converted to its active form (minoxidil sulfate), opens the ATP-dependent potassium channels in cells, causing a vasodilatation effect by increasing the production of vascular endothelial growth factor (VEGF) in dermal papillae, stimulating hepatocyte growth factor (HGF) production and activating the synthesis of prostaglandins, which are mechanisms that ultimately lead to stimulation of hair growth. ${ }^{28}$

Other therapeutic options include combination therapy. An interesting alternative was proposed recently by Vinaixa et al., who subjected non-obese women with PCOS to 3-month flutamide-metformin-pioglitazone polytherapy combined with ester-progestogen treatment, pointing to the benefit of such treatment with respect to the lipid profile (reduced LDL, increased HDL) higher androgen levels as well as increased carotid intima media (CIM) thickness, which in turn prevents the occurrence of atherosclerosis and related complications. ${ }^{29}$

Another alternative is the use of thiazolidinedione derivatives, which stimulate peroxisome proliferator-activated receptor type $\gamma$ (PPAR- $\gamma)$, enhance insulin sensitivity, reduce the level of glucose. However, these drugs do not reduce androgen levels and can contribute to patients' weight gain; in addition, they are contraindicated for women wishing to become pregnant. ${ }^{30}$

Encouraging results suggest that metformin combination therapy with new drugs acting on the incretin system (glucagon-like peptide receptor agonists 1-GLP-1, for example liraglutide or exenatide) leads to more effective weight reduction, lowers insulin resistance and improves reproductive function. However, they are still not registered as drugs with a high safety profile in women of reproductive age. ${ }^{31}$

Several studies have recently been published on the effectiveness of vitamin D supplementation, especially in 
autumn and winter. The authors have pointed out that vitamin D deficiency has an impact on the pathogenesis of insulin resistance in PCOS. ${ }^{32}$

Studies on the use of statins for the treatment of PCOS seem to be extremely encouraging, especially considering that approximately $70 \%$ of women with this syndrome are affected by lipid disorders and obesity. As blockers of 3-hydroxy-3-methylglutaryl-coenzyme A (HMG-CoA) reductase, statins have pleiotropic effects through their anti-inflammatory, antioxidant, antiproliferative and lipid-lowering activity. By blocking the formation of the malonic acid required for the synthesis of cholesterol, they inhibit the proliferation of cells in the ovarian theca cell layer, with a resultant reduction in the synthesis of steroid hormones. ${ }^{1}$ This was confirmed by the results of Celik and Acbay, who demonstrated that a 12-week combination therapy with metformin and rosuvastatin is more effective in reducing the testosterone, DHEA-S, body weight, CRP, TG and LDL cholesterol than the use of either of those drugs alone. ${ }^{33}$ Other authors compared the effects of different types of statins on selected endpoints. They proved, for example, that atorvastatin is more effective than simvastatin in improving insulin sensitivity, reducing the level of insulin in the fasting state, lowering blood pressure and reducing the concentration of advanced glycation end products (AGEs, which can affect the course of many diseases and degenerative processes). Atorvastatin also reduces the level of serum malondialdehyde (MDA) as a marker of oxidative stress. MDA is indirectly connected with the reduction of levels of CRP and total testosterone, and with increasing levels of 25-hydroxyvitamin D (25OHD) in PCOS patients. ${ }^{34,35}$

An interesting issue is the finding that supplementation with omega-3, $\alpha$-lipoic acid and $\mathrm{N}$-acetyl cysteine results in an antioxidant, anti-inflammatory effect, improves insulin sensitivity and the lipid profile of women with PCOS. ${ }^{36}$ Salehpour et al. demonstrated that N-acetyl cysteine lowers levels of testosterone, reduces androgen response to gonadotropin stimulation, improves ovulation rates and long-term health after 6 months of treatment. ${ }^{37}$

In recent years, attention has also been paid to the role of increased activity of the sympathetic nervous system in the pathogenesis, progression and treatment of PCOS. It has been shown that increased intraovarian production of nerve growth factor (NGF) and elevated muscle sympathetic nerve activity (MSNA) stimulate the development of obesity, hyperinsulinemia, obstructive sleep apnea (OSA) and metabolic disorders in PCOS patients. In these cases the use of non-pharmacological interventions (weight reduction, continuous positive airway pressure in OSA, electroacupuncture stimulation of baroreceptors), pharmacological treatment (drugs that increase insulin sensitivity) and surgical procedures (renal denervation) can bring surprising results..$^{38,39}$

Studies on the role of fibroblast growth factors (FGFs) in the pathogenesis of PCOS, metabolic disorders, type 2 diabetes and the cutaneous manifestations of hyperandrogenism represent an absolutely new approach. It has been shown that FGFs - particularly FGF-1, -10, -19 and -21 - are involved not only in the regulation of carbohydrate and lipid metabolism and show cardioprotective activity (FGF-21), but are also responsible for the cutaneous manifestations of excessive activity of the sebaceous glands. ${ }^{40}$ Decreased levels of FGF-19 have been observed among PCOS patients. An analog of FGF-21 called LY 2405319 , currently being tested in clinical settings, reduces insulin resistance and lowers blood glucose, cholesterol, triglycerides, LDL, and also helps in weight reduction. $^{41}$

In recent years, there have been reports concerning improvement in insulin sensitivity in women with PCOS due to myo-inositol treatment. It has been shown in some clinical trials that myo-inositol not only decreases glycemia in OGTT, the homeostatic model assessment (HOMA) index, and reduces the secretion of LH, DHEA, testosterone and progesterone but also improves the serum lipid profile (cholesterol, triglycerides). ${ }^{42}$ A high concentration of myo-inositol in the follicular microenvironment improves the availability of oocytes. Therefore myo-inositol restores menstrual regularity, ovulation and effectively increases the chances of getting pregnant. However, further studies are needed to be able to use myo-inositol for fertility treatment. ${ }^{42}$

Table 2 presents a summary of current and new medications, with their contraindications and possible side effects.

Table 2. Drug treatments for PCOS

\begin{tabular}{|c|c|c|c|}
\hline Drug & Effects & Contraindications & Side effects \\
\hline Metformin & $\begin{array}{l}\text { - restores regular bleeding and } \\
\text { ovulation } \\
\text { - reduces insulin resistance } \\
\text { - improves arterial tension values } \\
\text { - improves lipid profile } \\
\text { - shows antioxidant activity } \\
\text { - increases sex hormone binding } \\
\text { globulin (SHBG) level } \\
\text { - may help reduce body weight }\end{array}$ & $\begin{array}{l}\text { - hypersensitivity } \\
\text { - renal insufficiency } \\
\text { - acute or chronic diseases that may cause } \\
\text { tissue hypoxia, such as cardiac or respira- } \\
\text { tory insufficiency } \\
\text { - lactation } \\
\text { - hepatic damage }\end{array}$ & $\begin{array}{l}\text { - gastrointestinal disorders } \\
\text { - lactic acidosis } \\
\text { - dyspepsia, diarrhea, nausea, flatulence } \\
\text { - metallic aftertaste in the mouth }\end{array}$ \\
\hline
\end{tabular}


Table 2. Drug treatments for PCOS - cont.

\begin{tabular}{|c|c|c|c|}
\hline Drug & Effects & Contraindications & Side effects \\
\hline $\begin{array}{l}\text { Oral } \\
\text { Contraceptives }\end{array}$ & $\begin{array}{l}\text { - restore regular periods } \\
\text { - reduce symptoms of hyperan- } \\
\text { drogenism } \\
\text { - reduce risk of endometrial hyper- } \\
\text { plasia }\end{array}$ & $\begin{array}{l}\text { - past or current thromboembolic complica- } \\
\text { tions, cerebro- or cardiovascular disorders } \\
\text { - obesity (BMI over } 30 \mathrm{~kg} / \mathrm{m}^{2} \text { ) } \\
\text { - pregnancy or suspected pregnancy } \\
\text { - valvular heart disease } \\
\text { - active hepatic disease } \\
\text { - mammary or uterine cancer } \\
\text { - reproductive tract bleeding of unknown } \\
\text { etiology } \\
\text { - estrogen-dependent tumors }\end{array}$ & $\begin{array}{l}\text { - arterial hypertension } \\
\text { - nausea, vomiting } \\
\text { - headache } \\
\text { - dermal lesions (acne, hirsutism) } \\
\text { - body weight gain } \\
\text { - turgid breasts } \\
\text { - leg cramps } \\
\text { - vaginal staining or bleeding }\end{array}$ \\
\hline Clomifene & $\begin{array}{l}\text { - infertility treatment (ovulation } \\
\text { induction) }\end{array}$ & $\begin{array}{l}\text { - allergy to clomifene } \\
\text { - pregnancy } \\
\text { - hepatic disease } \\
\text { - primary hypopituitarism } \\
\text { - disturbed thyroid or adrenal function } \\
\text { - uterine bleeding of unknown etiology } \\
\text { - hormone-dependent tumors }\end{array}$ & $\begin{array}{l}\text { - headache, vertigo } \\
\text { - tiredness } \\
\text { - disturbed vision } \\
\text { - nausea, vomiting } \\
\text { - vasomotor symptoms } \\
\text { - facial flush } \\
\text { - mastalgia } \\
\text { - abdominal pain } \\
\text { - paramenia }\end{array}$ \\
\hline Eflornithine & - controls facial hirsutism & $\begin{array}{l}\text { - hypersensitivity to eflornithine or any } \\
\text { adjuvant }\end{array}$ & $\begin{array}{l}\text { - acne } \\
\text { - chronic folliculitis barbae } \\
\text { - alopecia } \\
\text { - skin burning sensation } \\
\text { - xerodermia } \\
\text { - itching } \\
\text { - erythema } \\
\text { - skin formication }\end{array}$ \\
\hline GnRH analogs & - inhibit androgens & $\begin{array}{l}\text { - hypersensitivity to any component of the } \\
\text { product or other GnRH analogues } \\
\text { - pregnancy or lactation } \\
\text { - metabolic disorders of the skeletal system }\end{array}$ & $\begin{array}{l}\text { - menopausal symptoms } \\
\text { - loss of bone mass } \\
\text { - vaginal dryness } \\
\text { - insomnia, mood swings, depression } \\
\text { - reduced libido }\end{array}$ \\
\hline Ketoconazole & - inhibits androgens & $\begin{array}{l}\text { - acute or chronic hepatic disease } \\
\text { - pregnancy or lactation }\end{array}$ & $\begin{array}{l}\text { - nausea } \\
\text { - alopecia } \\
\text { - dry skin } \\
\text { - uterine bleeding } \\
\text { - headache }\end{array}$ \\
\hline Steroids & - inhibit androgens & $\begin{array}{l}\text { - contraindicated in patients affected by } \\
\text { symptoms or diseases which may be a side } \\
\text { effect of their use, e.g. diabetes, hyperten- } \\
\text { sion, infections }\end{array}$ & $\begin{array}{l}\text { - adrenal suppression } \\
\text { - infections } \\
\text { - neuro-psychiatric abnormalities } \\
\text { - carbohydrate metabolism disorders, diabetes } \\
\text { - electrolyte imbalance } \\
\text { - osteoporosis } \\
\text { - changes in lipid and protein metabolism } \\
\text { - Cushing's syndrome } \\
\text { - gastric ulcer } \\
\text { - muscle weakness } \\
\text { - growth disorders in children } \\
\text { - glaucoma } \\
\text { - menstrual disorders }\end{array}$ \\
\hline Spironolactone & - inhibits androgens & $\begin{array}{l}\text { - hyperkalemia } \\
\text { - touch-sensitive nipples } \\
\text { - mastalgia } \\
\text { - menstrual disorders } \\
\text { - hirsutism } \\
\text { - agranulocytosis } \\
\text { - headaches } \\
\text { - sleepiness } \\
\text { - ataxia }\end{array}$ & $\begin{array}{l}\text { - hypersensitivity } \\
\text { - hyponatremia, hyperkalemia } \\
\text { - primary adrenal insufficiency } \\
\text { - severe renal and hepatic failure } \\
\text { - acute renal failure }\end{array}$ \\
\hline Flutamide & - inhibits androgens & $\begin{array}{l}\text { - hypersensitivity to any component of the } \\
\text { product }\end{array}$ & $\begin{array}{l}\text { - gynecomastia, mastalgia, galactorrhea } \\
\text { - diarrhea, nausea, vomiting, increased appetite } \\
\text { - insomnia, fatigue } \\
\text { - abnormal liver function }\end{array}$ \\
\hline
\end{tabular}


Table 2. Drug treatments for PCOS - cont.

\begin{tabular}{|c|c|c|c|}
\hline Drug & Effects & Contraindications & Side effects \\
\hline Finasteride & - reduces alopecia & $\begin{array}{l}\text { - hypersensitivity to any component of the } \\
\text { product } \\
\text { - pregnancy, planned pregnancy or breast- } \\
\text { feeding }\end{array}$ & $\begin{array}{l}\text { - decreased libido } \\
\text { - rash } \\
\text { - enlarged and tender breasts } \\
\text { - hypersensitivity reactions }\end{array}$ \\
\hline Isotretinoin & $\begin{array}{l}\text { - severe acne (due to reduced AMH } \\
\text { levels) }\end{array}$ & $\begin{array}{l}\text { - hypersensitivity to isotretinoin, peanuts, } \\
\text { soybeans or other ingredients } \\
\text { - pregnancy or lactation } \\
\text { - liver failure } \\
\text { - hypervitaminosis A } \\
\text { - increased blood lipid levels } \\
\text { - use of tetracycline antibiotics }\end{array}$ & $\begin{array}{l}\text { - dry skin and eyes with conjunctivitis } \\
\text { - dry mucous membranes, cheilitis } \\
\text { - contact lens intolerance } \\
\text { - anemia, accelerated ESR, increase in } \\
\text { transaminase activity } \\
\text { - itching, skin inflammation, rash, skin } \\
\text { hypersensitivity } \\
\text { - muscle and joint pain } \\
\text { - abnormal lipid profile }\end{array}$ \\
\hline Statins & $\begin{array}{l}\text { - pleiotropic effects (anti- } \\
\text { inflammatory, antioxidant, } \\
\text { antiproliferative and lowers the } \\
\text { level of lipids) } \\
\text { - inhibition of cell proliferation in } \\
\text { the theca layer of the ovaries and } \\
\text { reduction of steroid hormone } \\
\text { synthesis }\end{array}$ & $\begin{array}{l}\text { - active liver disease (ALT, AST exceeding } \\
3 \text { times the upper limit of normal values) } \\
\text { - pregnancy or lactation } \\
\text { - hypersensitivity }\end{array}$ & $\begin{array}{l}\text { - muscle damage (myopathy) } \\
\text { - increase in liver enzymes in the serum } \\
\text { - headache } \\
\text { - blurred vision } \\
\text { - insomnia } \\
\text { - ailments of the digestive tract } \\
\text { - rash } \\
\text { - joint pain }\end{array}$ \\
\hline $\begin{array}{l}\text { Fibroblast } \\
\text { growth factors } \\
\text { (FGFs) }\end{array}$ & $\begin{array}{l}\text { - regulation of carbohydrate and } \\
\text { lipid metabolism } \\
\text { - cardioprotection } \\
\text { - reduction of insulin resistance }\end{array}$ & - unknown & - unknown \\
\hline Vitamin D3 & - improves insulin sensitivity & - poisoning with or allergy to vitamin D & $\begin{array}{l}\text { - myocardial injury } \\
\text { - gastrointestinal symptoms: nausea, vomiting, } \\
\text { diarrhea } \\
\text { - hypercalciuria, polyuria, renal damage } \\
\text { - pain in the muscles or joints }\end{array}$ \\
\hline
\end{tabular}

\section{Summary}

Treatment of polycystic ovary syndrome, a disease affecting a significant part of the population of women worldwide, remains focused on specific targets, which may differ between individual women. The ideal would be causal treatment, but due to the ongoing lack of full understanding of the pathogenesis of the syndrome, is not entirely feasible. However, the increasing amount of research and continually refined new therapeutic options mean that the effects of the available therapies are improving. Despite this, unfortunately, none of them is able to completely eliminate all the symptoms and adverse consequences of PCOS. A comprehensive approach, regular check-ups to prevent remote effects of the disease and a healthy, active lifestyle seem to be the best possible solution.

\section{References}

1. Wołczyński S, Zgliczyński W. Abnormalities of the menstrual cycle. In: Large Interna - Endocrinology. $2^{\text {nd }}$ edition. Medical Tribune Poland, Warsaw 2012, 561-567.

2. The Rotterdam ESHRE/ASRM-sponsored PCOS consensus workshop group. Revised 2003 consensus on diagnostic criteria and long-term health risks related to polycystic ovary syndrome (PCOS). Hum Reprod. 2004;19(1):41-47. doi: 10.1093/humrep/deh098.

3. Milewicz A. Reimbursement of metformin for polycystic ovary syndrome. EndokrynolPol. 2013;64(5):409-414. doi: 10.5603/EP.2013.0025.
4. Morotti E, Battaglia B, Fabbri R, Paradisi R, Venturoli S, Battaglia C. Cigarette smoking and cardiovascular risk in young women with polycystic ovary syndrome. Int J Fertil Steril. 2014;7(4):301-312. https://www.ncbi.nlm.nih.gov/pmc/articles/PMC3901187 [Published online 2013 Dec 22].

5. Davies MJ, Marino JL, Willson KJ, March WA, Moore VM. Intergenerational associations of chronic disease and polycistic ovary syndrome. PLoS One. 2011;6(10):e25947. doi: 10.1371/journal.pone. 0025947.

6. Tan S, Scherag A, Janssen OE et al. Large effects on body mass index and insulin resistance women with PCOS (FTO) variants in patients with polycystic ovary syndrome (PCOS). BMCMed Genet. 2010;11:12. doi: 10.1186/1471-2350-11-12.

7. Fica S, Albu A, Constantin M, Dobri GA, Davila C. Insulin resistance and fertility in polycystic ovary syndrome. J Med Life. 2008;1(4):415422. https://www.ncbi.nlm.nih.gov/pmc/articles/PMC3018970/ Published online 2008 Nov 25.

8. Traub ML. Assessing and treating insulin resistance in women with polycystic ovarian syndrome. World J Diabetes. 2011;2(3):33-40. doi: 10.4239/wjd.v2.i3.33.

9. Sathyapalan T, Atkin ST. Mediators of inflammation in polycystic ovary syndrome in relation to adiposity. Mediat Inflamm. 2010;2010: 758656. doi: 10.1155/2010/758656.

10. McClung J, Karl P. Iron deficiency and obesity: The contribution of inflammation and diminished iron absorption. Nutr Rev. 2009;67: 100-104. doi: 10.1111/j.1753-4887.2008.00145.x.

11. Bentley-Lewis R, Selly E, Dunaif A. Ovarian hypertension: Polycystic ovary syndrome. Endocrinol Metab Clin North Am. 2011;40:433-449. doi: 10.1016/j.ecl.2011.01.009.

12. Krępuła K, Bidzińska-Speichert B, Lenarcik A, Tworowska-Bardzińska U. Psychiatric disorders related to polycystic ovary syndrome. Pol J Endocrinol. 2012;63(6):488-491.

13. Dumesic DA, Lobo RA. Cancer risk and PCOS. Steroids. 2013;78(8): 782-785. doi: 10.1016/j.steroids.2013.04.004. 
14. Stovall DW, Bailey AP, Pastore LM. Assessment of insulin resistance and impaired glucose tolerance in lean women with polycystic ovary syndrome. J Womens Health. 2011;20(1):37-43. doi: 10.1089/ jwh.2010.2053.

15. Sidhwani S, Scoccia B, Sunghay A, Stephens-Archer CN, Mazzone T, Sam S. PCOS is associated with atherogenic changes in lipoprotein particle number and size independent of body weight. Clin Endocrinol. 2011;75:76-82. doi: 10.1111/j.1365-2265.2011.04015.x.

16. Bu Z, Kuok K, Meng J, Wang R, Xu B, Zhang H. The relationship between polycystic ovary syndrome, glucose tolerance status and serum preptin level. Reprod Biol Endocrine. 2012;10:10. doi: 10.1186/ 1477-7827-10-10.

17. Domecq JP, Prutsky G, Mullan RJ. Lifestyle modification programs in polycystic ovary syndrome: Systematic review and meta-analysis. J Clin Endocrinol Metab. 2013;98(12):4655-4663. doi: 10.1210/jc. 2013-2385.

18. Kahal H, Atkin SL, Sathyapalan T. Pharmacological treatment of obesity in patients with polycystic ovary syndrome. J Obes. 2011: 402052. doi: 10.1155/2011/402052.

19. Beck E, Scheen AJ. Metformin, an antidiabetic molecule with anticancer properties. Rev Med Liege. 2013;68(9):444-449.

20. Chung HH, Moon JS, Yoon JS, Lee HW, Won KC. The relationship between metformin and cancer in patients with type 2 diabetes. Diabetes Metab J. 2013;37(2):125-131. doi: 10.4093/dmj.2013. 37.2.125.

21 Badr D, Kurban M, Abbas O. Metformin in dermatology: An overview. J Eur Acad Dermatol Venereol. 2013;Nov, 27:1329-1335. doi: 10.1111/jdv.12116.

22. Tang T, Glanville J, Hayden CJ, White D, Barth JH, Balen AH. Combined lifestyle modification and metformin in obese patients with polycystic ovary syndrome: A randomized, placebo-controlled, double-blind multicentre study. Hum Reprod. 2006;21:80-89. doi: 10.1093/humrep/dei311.

23. Oppelt PG, Mueller A, Jentsch K, et al. The effect of metformin treatment for 2 years without caloric restriction on endocrine and metabolic parameters in women with polycystic ovary syndrome. Exp Clin Endocrinol Diabetes. 2010;118:633-637. doi: 10.1055/s-00291237705.

24. Malik SM, Traub M. Defining the role of bariatric surgery in polycystic ovarian syndrome patients. World J Diabetes. 2012;3(4):71-79. doi: 10.4239/wjd.v3.i4.71.

25. Wolf JE, Shander D, Huber F, et al. Randomized, double-blind clinical evaluation of the efficacy and safety of topical eflornithine $\mathrm{HCl}$ $13.9 \%$ cream in the treatment of women with facial hair. Int J Dermatol. 2007;46:94-99. doi: 10.1111/j.1365-4632.2006.03079.x.

26. Cakir GA, Erdogan FG, Gurler A. Isotretinoin treatment in nodulocystic acne with and without polycystic ovary syndrome: Efficacy and determinants of relapse. Int J Dermatol. 2013;Mar;52(3):371376. doi: 10.1111/j.1365-4632.2012.05691.x.

27. Çetinözman F, Yazgan AD, Elçin G, YildizBO. Insulin sensitivity, androgens and isotretinoin therapy in women with severe acne. J Dermatolog Treat. 2014;25(2):119-122. doi: 10.3109/09546634.2012.751482.

28. Vexiau P, Chaspoux C, Boudou P, et al. Effects of minoxidil $2 \%$ vs. cyproterone acetate treatment on female androgenetic alopecia: A controlled, 12-month randomized trial. Br J Dermatol. 2002, 146(6):992-999. doi: 10.1046/j.1365-2133.2002.04798.x.

29. Vinaixa $M$, Rodriguez $M A$, Samino $S$ et al. Metabolomics reveals reduction of metabolic oxidation in women with polycystic ovary syndrome after pioglitazone-flutamide-metformin polytherapy. PLoS One. 2011;6(12):e29052. doi: 10.1371/journal.pone.0029052.
31. Du Q, Yang S, Wang YJ, Wu B, Zhao YY, Fan B. Effects of thiazolidinediones on polycystic ovary syndrome: A meta-analysis of randomized placebo-controlled trials. Adv Ther. 2012;29(9):763-774. doi: 10.1007/s12325-012-0044-6.

31. Jensterle Sever M, Kocjan T, Pfeifer M, Kravos NA, Janez A. Shortterm combined treatment with liraglutide and metformin leads to significant weight loss in obese women with polycystic ovary syndrome and previous poor response to metformin. Eur J Endocrinol. 2014;170(3):451-459. doi: 10.1530/EJE-13-0797.

32. Thomson RL, Spedding S, Brinkworth GD, Noakes M, Buckley JD. Seasonal effects on vitamin D status influence outcomes of lifestyle intervention in overweight and obese women with polycystic ovary syndrome. Fertil Steril. 2013;99(6):1779-1785. doi: 10.1016/j. fertnstert.2012.12.042.

33. Celik O, Acbay O. Effects of metformin plus rosuvastatin on hyperandrogenism in polycystic ovary syndrome patients with hyperlipidemia and impaired glucose tolerance. J Endocrinol Invest. 2012;35(10):905-910. doi: 10.3275/8371.

34. Sathyapalan T, Shepherd J, Coady AM, Kilpatrick ES, Atkin SL. Atorvastatin reduces malondialdehyde concentrations in patients with polycystic ovary syndrome. J Clin Endocrinol Metab. 2012;97(11): 3951-3955. doi: 10.1210/jc.2012-2279.

35. Kimura $\mathrm{Y}, \mathrm{Hyog}$ o $\mathrm{H}$, Yamagishi $\mathrm{S}$, et al. Atorvastatin decreases serum levels of advanced glycation endproducts (AGEs) in nonalcoholic steatohepatitis (NASH) patients with dyslipidemia: Clinical usefulness of AGEs as a biomarker for the attenuation of NASH. J Gastroenterol. 2010;45(7):750-757. doi: 10.1007/s00535-010-0203-y.

36. Macut D, Bjekić-Macut J, Savić-Radojević A. Dyslipidemia and oxidative stress in PCOS. Front Horm Res. 2013;40:51-63. doi: 10.1159/ 000341683.

37. Salehpour S, Tohidi M, Akhound MR, Amirzargar N. N-acetylcysteine: A novel remedy for polycystic ovarian syndrome. Int J Fertil Steril. 2009,3:66-73. https://www.researchgate.net/publication/ 228674382_N_Acetyl_Cysteine_A_novel_Remedy_for_Poly_Cystic_ Ovarian_Syndrome. Accessed 23 Aug 2009.

38. Lansdown A, Rees DA. The sympathetic nervous system in polycystic ovary syndrome: A novel therapeutic target? Clin Endocrinol (Oxf). 2012;77(6):791-801. doi: 10.1111/cen.12003.

39. Schlaich MP, Straznicky N, Grima M, et al. Renal denervation: A potential new treatment modality for polycystic ovary syndrome? J Hypertens. 2011;29(5):991-996. doi: 10.1097/HJH.0b013e328344db3a.

40. Katoh M. FGFR2 abnormalities underlie a spectrum of bone, skin, and cancer pathologies. J Invest Dermatol. 2009;129:1861-1867. doi: 10.1038/jid.2009.97.

41. Kharitonenkov A, Adams AC. Inventing new medicines: The FGF21 story. Mol Metab. 2014;3:221-229. doi: 10.1016/j.molmet.2013.12. 003.

42. Unfer V, Carlomagno G, Dante G, et al. Effects of myo-inositol in women with PCOS: A systematic review of randomized controlled trials. Gynecol Endocrinol. 2012;28(7):509-515. doi: 10.3109/ 09513590.2011.650660.

43. Erin Barthelmess Rajesh KN. Polycystic ovary syndrome: Current status and future perspective. Front Biosci. 2014;6:104-119. https:// www.ncbi.nlm.nih.gov/pmc/articles/PMC4341818/. Published online 2014 Jan 1.

44. Sunita J. Ramanand, Balasaheb B. Ghongane, Jaiprakash B. Ramanand, et al. Clinical characteristics of polycystic ovary syndrome in Indian women. Indian J Endocrinol Metab. 2013;17(1):138-145. doi: $10.4103 / 2230-8210.107858$. 